\title{
Algernon Sidney: a tensão entre virtude e legalidade
}

Luís Falcão

\author{
Luís Falcão \\ Doutor em Ciência Política pelo IESP/UERJ. Professor \\ da Universidade Federal Fluminense. \\ Email: luis.alves.falcao@gmail.com \\ ORCID: http://orcid.org/0000-0003-3785-626X
}

\begin{abstract}
Resumo
O artigo explora a relação entre o governo do homem de virtude e o governo das leis no pensamento de Algernon Sidney. Para ele, diferentemente de outros republicanos, o primeiro deve ter primazia sobre o segundo sempre que a virtude se apresentar como uma possibilidade.

Contudo, a dificuldade prática que isso envolve conduz ao imperativo de se reconhecer o governo das leis como necessário. $O$ estudo busca mostrar também as condições nas quais leis e virtude são mutuamente compatíveis.
\end{abstract}

\section{Palavras-chave}

Algernon Sidney, Governo, Virtude, Lei, Republicanismo

\begin{abstract}
The paper explores the relationship between the government of a virtuous man and the government of laws in the thought of Algernon Sidney. For him, unlike other republicans, the former should take precedence over the second where the virtue presents itself as a possibility. However the practical difficulty that this involves leads to recognize the necessity of the government of laws. The study also seeks to show the conditions under which laws and virtue are mutually compatible.
\end{abstract}

\section{Key-words}

Algernon Sidney, Government, Virtue, Law, Republicanism

"Quem quer saber do que está escondido procura no fundo dos olhos do povo e dentro do seu coração." 
Ednardo, Pastora do Tempo, 1977.

\section{Introdução}

A reconstrução histórica da linguagem do republicanismo moderno tem encontrado, nas últimas décadas, forte ambivalência entre o vocabulário da virtude e o das instituições. Deriva-se dessa primeira linguagem todo um campo semântico valorativo do bem comum, da dedicação à coisa pública, da abnegação, do civismo participativo e da cidadania. Nesse sentido, o republicanismo poderia ser entendido como uma tradição do pensamento político diretamente associada às ações dos homens virtuosos, em sua formulação da vita activa como prioritária à vita contemplativa. A dimensão política dessa assertiva se torna latente na medida em que se identifique a importância da virtude, a sua definição e suas consequências, como a maneira central de compreensão do fundamento último do republicanismo, como expressa nas interpretações de J. G. A. Pocock, por exemplo. Por outro lado, não é incomum encontrar estudos que partam da identificação do republicanismo, ou do regime republicano, como um governo das leis em oposição ao governo dos homens. Nesse caso, o entendimento dessa tradição se vincula, antes das práticas dos homens, às instituições. Porém, mesmo autores como Quentin Skinner e Philip Pettit, proeminentes defensores desse segundo modo interpretativo, reconhecem a importância da virtude, em nível instrumental e como meio a fim de atingir um objetivo maior, a liberdade. Se, por um lado, este campo semântico se apresenta nas pesquisas recentes comumente aderente a uma perspectiva constitucional e de cunho institucionalista, por outro, aquele que destaca a virtude tende a priorizar a atividade política e a democracia (Geuna, 2013; Peña, 2004; Pinzani, 2005). Este artigo não pretende abordar tais divergências nas reconstruções recentes, apenas admite a constatação de que lei e virtude são dois termos destacados do republicanismo moderno e, em alguns casos, se mostram antagônicos.

É necessário ter em conta, todavia, que a articulação entre o governo das leis e o governo dos virtuosos jamais se mostrou uma tarefa simplória. Pelo contrário, as resoluções, via de regra, se desenvolvem a partir de critérios externos à própria lei e virtude, seus conceitos e empregos. $O$ exemplo de Maquiavel é bastante esclarecedor nesse ponto. A virtude, para ele, possui primazia lógica sobre o governo das leis, visto que a fundação da cidade e seu bom ordenamento requer situações capazes de promovê-la, seja a partir um homem isoladamente, seja a partir do conflito político. Estabelecidas as ordens centrais da república, as leis se fazem necessárias a fim de garantir seu devido andamento institucional. Assim, não depende a boa ordenação republicana de um conteúdo generalizável e atemporal da virtude ou de quais sejam as leis em voga, tão pouco se pode afirmar que a virtude e a lei convivam harmonicamente. Antes disso, a existência de uma ou de outra depende das condições nas quais surgem, nas quais uma depende da outra, embora o convívio de ambas seja exceção. Sem descartar as particularidades, evidentemente, uma perspectiva semelhante ocorre com, digamos, Francesco Guicciardini e James Harrington. De fato, tal ambivalência existente em diversos autores republicanos reflete a importante tensão entre o governo do homem de virtude, capaz de conduzir sua cidade à glória e à grandeza, e o governo das leis, artifício desenvolvido a fim promover legitimidade e obliterar arbitrariedades. Em que medida o governo dos virtuosos subverte a ordem legal produzindo desigualdades ou, inversamente, em que medida a constitucionalidade de um regime limita e obstrui determinadas ações necessárias em contextos de crise são questões de constante preocupação entre os republicanos. Nesse conjunto de pensadores, certamente, alguns, mais do que outros, dedicaramse a enfrentar a problemática. Dentre eles, Algernon Sidney ofereceu uma posição peculiar e que se pretendia definitiva na coadunação do republicanismo com o jusnaturalismoi. Ao contrário dos exemplos acima referidos, Sidney busca uma conciliação entre lei e virtude cujo critério distintivo se embasa nos seus próprios conceitos. Em outras palavras, não obstante a tensão entre os conceitos permanecer evidente, Sidney propõe uma solução estável e perene, que independa do contexto de previsibilidade ou de crise. 
Portanto, o objetivo desse artigo é explorar a relação entre o governo dos virtuosos e o governo das leis no pensamento deste autor, atento aos termos de seu republicanismo. Não se trata meramente de um estudo exegético da obra de Sidney, o que em si mesmo já justificaria toda a empreitada, mas de sua singularidade na resolução entre essa tensão, que, não obstante a centralidade de seu republicanismo, flerta com os argumentos monarquistas do bom governante. $O$ texto se divide em três partes: 1 ) as leis da natureza que permitem compreender o modo pelo qual a razão e a virtude podem ser subvertidas ou associadas; 2) o conceito de virtude e sua aplicação ao bom governo; 3) os argumentos a favor do governo das leis. Por fim, o artigo é concluído com uma consideração a respeito da compatibilidade entre o governo dos homens virtuosos e o governo das leis em contraste com argumentos tipicamente monárquicos.

\section{Lei da natureza como liberdade e como razão}

Não obstante existir uma variedade de definições e aplicações de lei da natureza na obra de Sidney, é possível sintetizá-las de modo crescente da mais abrangente à mais particular, ou da mais complexa à mais simples. A primeira delas diz respeito à situação inescapável de todo ser humano nascer livre. Desse modo, o caráter impositivo da lei da natureza é a condição humana de liberdade, já que os homens desfrutam de "completa fruição de sua liberdade natural" (Sidney, 1996b, p. 103), de tal maneira que o conteúdo de suas ações não seja a priori prescrito: "temos em nós mesmos o poder de sermos a agirmos mal" (Sidney, 1795, p. 276). Seria desnecessário reproduzir e comentar as inúmeras vezes nas quais Sidney emprega a definição. Basta que se tenha claro que é condição natural dos homens estarem livres para agirem ou não agirem de acordo com o que Ihes convier, com o que lhes for melhor ou assim Ihes parecer. "Sobre a [ação] voluntária, ela nada significa além da liberdade, todos os atos humanos são livres ou não livres, isto é, advindos da vontade da pessoa ou de algum impulso de fora. Se, então, não houver emprego da força àqueles que são livres nem àqueles que são não livres, não há nenhuma restrição" (Sidney, 1996b, p. 413). Assim, o primeiro ditame da lei da natureza em Sidney se assemelha bastante à definição hobbesiana de liberdade: ausência de impedimentos externosii.

No sistema hobbesiano, a razão assume um papel de destaque, uma vez que é ela que estabelece o preceito ou regra geral que Hobbes (1985, p. 80) identifica como a lei da natureza. Em Sidney, o preceito racional é o mesmo, embora sua definição de razão não seja exatamente a mesma da de Hobbes. "Não é a lei da natureza uma regra que ele [Deus] deu às coisas? E a lei da natureza do homem, que é liberdade, uma emanação da sabedoria divina ou alguma reminiscência da luz divina permanecente em nós?" (Sidney, 1996b, p. 338). Diferentemente de Hobbes - que pretende tornar evidente a natureza racional dos homens pelo fato de saberem contar e, voltados para a autodefesa, os homens a empregam livremente -, Sidney embute um caráter moral e sábio nessa racionalidade. Por natureza, todos os homens são capazes de diferenciar o bem do mal, 0 justo do injusto, o certo do errado e é isso o caráter distintivo da humanidade frente aos outros seres, pois é neste ponto em que mais se aproxima da divindade (Sidney, 1996b, p. 122 e 281) )ii. $^{\text {ii. }}$ "O homem é, por natureza, uma criatura racional. Então, tudo que é irracional é contrário à natureza do homem" (Sidney, 1996a, p. 33).

É uma constante da condição humana estar embutido de razão. Esta mesma razão não apenas aponta os caminhos e ações auto defensivas para cada um, mas também afirma o deverser do bem, do justo e do correto. Portanto, a lei da natureza é composta de duas partes que moldam e condicionam os homens em suas vidas na terra. Primeiramente, ela garante que eles sejam livres, que se movimentem e ajam como queiram, sem quaisquer impedimentos senão quando limitados fisicamenteiv. Em segundo lugar, embute em cada um a capacidade racional de identificar os fundamentos morais da vida ordinária. Portanto, para Sidney, a lei da natureza se bifurca em duas versões, o que o difere do lugar-comum da linguagem jusnaturalista dos seiscentos inglês. Todavia, essas duas vertentes da lei da natureza não são igualmente potentes. Pelo contrário, a existência da primeira condiciona os preceitos de segunda. Dado que o homem é 
livre para agir como queira, não poderia ele simultaneamente ser obrigado a seguir um comportamento moral oriundo, em última instância, de Deus. Assim, a lei da natureza como liberdade faz com que a lei da natureza como razão possa ser descumprida ou mesmo desrespeitada por qualquer um que tenha apenas a capacidade para tal. Em suma, basta alguém estar desimpedido fisicamente e ter a capacidade física para que a lei natural como razão seja desrespeitada.

Os mais sábios e melhores sempre empregaram seus estudos na formação de reinos e repúblicas ou no aperfeiçoando dos já constituídos, embora fossem contrários às leis de Deus e da natureza. Se uma regra geral que obrigasse todos a serem sempre sujeitos a um homem foi estabelecida, então, eles não eram os melhores, mas os piores homens que o fizeram. (Sidney, 1996b, p. 112)

Contrários à lei da natureza e de Deus, os homens já estabeleceram reinos e repúblicas, mas esta lei da natureza é um preceito e não uma imposição. Assim, a lei da natureza como razão não impõe, mas conduz aquele que deseja seguir o caminho divino. Ela pode ser desenvolvida por qualquer um que, sob condições de uma vida regrada e meditativa, possa se dedicar à sua compreensão, necessitando apenas que consultem o próprio coração, pois Deus a escreveu nele (Sidney, 1795, p. 280; Sidney, 1996b, p. 22). Por isso, é a "lei da natureza que deve ser o guia para minha consciência" (Sidney, 1996b, p. 419). O fato de a lei da natureza como liberdade ser mais potente do que a lei da natureza como razão produz a contradição interna descrita acima: ser livre para agir contra a razão. Mas, duas são as situações nas quais as duas leis da natureza não se mostram divergentes nem contraditórias.

Primeiramente, quando os homens, utilizando de suas faculdades naturais da razão, atribuem ao(s) mais virtuoso(s) o governo pelo consentimento, porque reconhecem nele(s) a capacidade de melhor gerir os negócios públicos de modo a produzir o bem comum (Sidney, 1996b, cap. II, seções 1 e 15) ${ }^{v}$. Mas, para isso, seria necessário que todos os homens, sem exceção, sejam capazes de mobilizar a razão natural para que reconheçam aqueles de virtude superior e, assim, conduzi-los ao governo (Scott, 1988, p. 191). Nessa situação, os homens continuam livres porque governados por virtuosos, que, por definição, não tolherão a liberdade alheia (Sidney, 1996a, p. 4). Ainda assim, tal situação é meramente circunstancial, uma vez que, mesmo consultando o coração, os homens podem se negar a segui-lo. A faculdade da qual todos desfrutam de conhecer o bem, o justo e o correto não faz com que os homens ajam em sua conformidade. Mas quando o fazem, reconhecem as distinções naturais de virtude e atribuem aos mais capacitados o comando da comunidade e isso é tanto válido para uma seita, um exército ou para uma cidade ou um país inteiros.

O segundo modo pelo qual as duas leis da natureza se mostram compatíveis entre si se faz a partir da inevitável e impositiva soberania do virtuoso: "a virtude apenas pode dar uma preferência justa e natural; eu ingenuamente confesso que quando um homem ou raça de homens, assim como ele [Aristóteles] descreve, aparecer no mundo, eles podem carregar a verdadeira marca da soberania" (Sidney, 1996b, p. 81). O exemplo a que Sidney se refere não é nada menos que Alexandre, o Grande, quem foi capaz de unir sua força militar com sua virtude, o que é bastante diferente de afirmar que todos aqueles virtuosos são igualmente competentes nas artes militares da conquista (Sidney, 1996b, p. 487). Esta segunda compatibilidade se mostra igualmente frágil e, se fosse possível generalizá-la, expressaria uma efetiva inutilidade para com a necessidade do consentimento, já que a força se impõe e configura o melhor dos governos. A questão se mostra ainda mais interessante quando Sidney se propõe a responder se a situação do conquistador macedônio seria capaz de produzir o governo bom e justo: "É melhor para nós sermos guiados por ele do que seguirmos nosso próprio julgamento; eu quase poderia dizer: seria melhor servir um mestre assim do que ser livre" (Sidney, 1996b, p. 81).

Teoricamente, a rigor, não importa como o homem virtuoso atingiu o poder, por 
consentimento ou força, mas que, de fato, seja ele quem governe. Nesse sentido, fica evidente que Sidney admite a completa alienação da liberdade natural, se, e apenas se, ela for voluntária, unilateral e voltada para o bem de quem se aliena a si mesmo e porquanto esse bem for assim reconhecido pelo próprio alienadovi. Portanto, não obstante a lei da natureza como liberdade ser uma imposição e o cumprimento da lei da natureza como razão ser uma contingência, há a possibilidade de inversão dessa hierarquia quando se trata da superioridade do bem em situação análoga à da escravidão, isto é, quando alguém por si mesmo reconhecer que é melhor ser escravo do que livre.

Ambas as soluções, pelo consentimento ou pela força, que compatibilizam a lei da natureza como liberdade e a lei da natureza como razão, são plausíveis, mas apenas contingencialmente, de modo que os dois caminhos estão disponíveis para a humanidade, embora a dificuldade de realizálos seja latente. $O$ que parece surpreender o leitor familiarizado com teorias jusnaturalistas é que Sidney não propõe uma solução definitiva, una e universal, mas se limita a resoluções contingenciais apresentadas acima. "A diferença, então, entre o governo bom e o ruim não é que um tipo tem um poder arbitrário que os outros não têm, pois, todos o têm, mas está naqueles governos bem constituídos que alocam seu poder de tal modo que seja benéfico ao povo" (Sidney, 1996b, p. 570).

Uma vez que todo e qualquer governo possui, em certo nível, alguma arbitrariedade, resta apenas que ele seja bem constituído (Sidney, 1996b, p. 542). Nesse sentido, arbitrário é tudo aquilo que possui sua origem nos homens, como o próprio governo e as leis positivas, já que "elaborar a forma de uma boa lei é tema de invenção e julgamento" (Sidney, 1996b, p. 573; cf. Sidney e Jones, 1689, p. 175). A questão fundamental, que a princípio pode se mostrar paradoxal, é justificar quem seria o agente capaz de definir ou reconhecer se e quando um homem deve ou não se submeter ao juízo de outro(s). Não há, em Sidney, um agente externo, neutro e onisciente que intervenha nos negócios humanos, estes estão sós na vida terrena com tanta liberdade que pode causar mais males do que bens. $O$ único juiz legítimo de uma causa que interfira em alguém é a própria pessoa que sofre a intervenção. Portanto, para concluir essa parte do argumento, é preciso reconhecer que a lei da natureza como liberdade é mais potente do que a lei da natureza como razão, mas apenas a razão humana é capaz de tolher a liberdade legitimamente e para benefício de quem é tolhido, seja o comando estabelecido pelo consentimento ou pela força.

\section{A virtude e seu governo}

As duas compatibilidades conduzem ao governo do mais virtuoso que, devido à origem humana, não é menos arbitrário do que o governo das leis, que, como civis, são igualmente humanas. Nesse momento, se faz necessário inserir um elemento importante para a compreensão da justificativa para o governo dos homens em detrimento do governo das leis. Parece claro que, para Sidney, o melhor dos governos é aquele que não se prende a limites legais, aquele que conduz a melhorias incrementais e sustenta a liberdade. Para tal, é imprescindível que se entenda como a virtude é distribuída e seu caráter contingencial e mundano.

A compreensão de como a virtude assume intensidades diferentes nos diferentes homens é diretamente inspirada em Aristóteles, em suas avaliações das formas de governo que congregam maiores quantidades de virtude. "Aristóteles aplaude muito a monarquia: quando um monarca tem mais daquelas virtudes que levam ao bem da sociedade política do que aqueles que a compõem" (Sidney, 1996b, p. 132; cf. Worden, 1985, p. 24). A referência é à Ética Nicomaqueia (1160 b) e à Politica (1288a). Acompanhando as passagens do estagirita, Sidney escreve:

Ele ou eles têm mais dessas virtudes e excelências computadas conjuntamente do que o resto da sociedade: onde esse homem é encontrado, ele é, por natureza, um rei. E é melhor para uma nação que seja ele o governante. Se alguns homens, embora iguais e semelhantes entre si, tiverem as mesmas vantagens sobre o resto do povo, a natureza, 
pela mesma razão, parece estabelecer uma aristocracia naquele lugar e o poder está mais seguro neles do que nas mãos da multidão. Mas se essa excelência de virtude não aparecer em um nem em alguns, o direito e o poder são, por natureza, igualmente depositados em todos, e receber ou depositar o poder em um ou alguns homens é antinatural e tirânico, o que na linguagem de Aristóteles compreende tudo que é detestável e abominável. (Sidney, 1996b, p. 453)

Por isso, o governo é tão bom quanto seus governantes possuam virtude e a tríade clássica das formas de governo é definida por sua distribuição. Uma vez que é a virtude a distinção fundamental daqueles que governam, é também o melhor dos governos possíveis, dependendo de como seja distribuída. Repare-se que todo regime pautado no critério da virtude é natural, ou seja, a natureza estabelece quem e quantos são governantes em todas as situações hipotéticas: quando concentrada, em um ou em poucos, tem-se, respectivamente uma monarquia e uma aristocracia. O governo de todos, também chamado de governo popular ou misto (cf. Barros, 2018, p. 115), é o único caso que independe da quantidade absoluta de virtude, é necessário apenas que ela seja relativamente bem distribuída entre os homens. Desse modo, se todos forem muito ou pouco virtuosos em si mesmos, não faz diferença, pois trata-se do governo das leis que rege a todos igualmente. "[O rei] deve governar, porque é melhor para o povo ser governado por ele do que desfrutar de sua liberdade, se é que ele desfruta de sua liberdade, que nunca é mais segura do que quando é defendida por alguém que é uma lei viva para si mesmo e para os outros" (Sidney, 1996b, p. 132). A passagem é bastante contundente e refere-se a duas consequências do governo do mais virtuoso. Primeiramente, é melhor para um povo ser governado por aquele que possui mais virtude do que a soma de todas as outras virtudes do que viver em liberdade, isto é, viver em sociedade e sem qualquer regramento. Em outros termos, a situação na qual a lei da natureza como razão é cumprida é superior à situação na qual apenas a lei da natureza como liberdade seja efetiva. Em segundo lugar, nessa situação, o rei não é nada além do que uma "lei viva", já que parte dele toda autoridade governamentalvii. Essa perspectiva supõe que, uma vez que o rei seja efetivamente virtuoso, as leis não Ihe tolhem a autoridade e operam em conformidade com sua virtude. "A lei, assim, prevê deixar ao rei um completo e amplo poder de fazer tanto bem quanto seu coração desejar, e a nação não perece quando [a lei] restringir seus poderes de modo que ele se afaste de seu ofício quando deve" (Sidney, 1996b, p. 390). Mas se o rei não for virtuoso, e, portanto, não tiver a legitimidade para exercer o cargo, as leis limitam ou mesmo o depõem de seu poder (Sidney, 1996a, p. 64; Sidney, 1996b, p. 389) viii. Como encarnação da lei viva, o virtuoso a possui tão somente como um recurso governamental. Por conseguinte, na circunstância em que a virtude encontra-se radicalmente concentrada, a escolha entre a liberdade do estado de natureza e a segurança e o bem promovidos pela entrada em sociedade deixa de ser profunda e se ameniza (Hamel, 2011, p. 77), porque a lei deixa de ser um critério externo e limitador da arbitrariedade parcial e passa a ser os atos e comandos do virtuoso.

Nesse ponto, compreende-se a complementariedade entre as leis e a virtude. Sob determinadas circunstâncias, a lei viva não é outra senão a vontade do governante virtuoso e é somente na situação na qual o governo é o do(s) mais virtuoso(s), e por isso as leis são apenas seus instrumentos administrativos (Sidney, 1996a, p. 133), que elas são compatíveis com a virtude, porque consequência desta. No caso inverso - quando não se encontram homens significativamente mais virtuosos do que os demais -, a única maneira de obliterar arbitrariedades é através de uma lei externa, à qual todos, incluindo os governantes, se submetam. Estabelecida a teoria, os problemas práticos emergem.

"Sidney evoca Aristóteles para justificar a assertiva de que nenhum homem é suficientemente livre de paixões para resistir às tentações do poder irrestrito" (Houston, 1991, p. 154; cf. Sidney, 1996b, p. 358-360). De fato, esta é uma preocupação constante de Sidney. Qualquer homem, reis, sábios e virtuosos inclusos, está submetido à possibilidade de ceder às 
paixões e aos devaneios da vida comum (Barros, 2018, p. 116; Carrive, 2007, p. 113). As "histórias estão repletas desses homens sábios, que, para além de toda a pretensa austeridade, caíram profundamente no poder da paixão" (Sidney, 1795, p. 273). Não se trata apenas de um conjunto de sentimentos que provoca o desregramento da razão e compromete a virtude, mas também das circunstâncias de vidaix.

E como é loucura supor que os príncipes sempre serão sábios, justos e bons, quando sabemos que poucos foram capazes de sustentar sozinhos 0 peso de um governo ou de resistir às tentações do mal que acompanham o poder ilimitado, seria loucura presumir que, no futuro, seriam livres de fraquezas e vícios. (Sidney, 1996b, p. 442; cf. Sidney, 1996b, p. 447)

Uma vez esclarecidas as explicações generalistas, Sidney se defronta com a historicidade e plausibilidade empírica de suas próprias colocações (Winship, 2010, p. 769). "Mas ele [Aristóteles] admite que se esse homem não for encontrado, não existe rei natural" (Sidney, 1996b, p. 132). Segue-se, então, um enumerado de critérios e condições nas quais a teoria do melhor governo pelo mais virtuoso encontra seus limites (Sidney, 1996b, p. 453), baseados nas análises de Aristóteles (Política, 1284a) sobre a justeza do comando entre iguais e entre desiguais. Esses são argumentos de ordem contingencial e histórica. Como saber, a priori, quem é o mais virtuoso, como encontrá-lo ou ainda como ter certeza de que ele existe são as barreiras práticas que tendem a fazer com que se acolha o governo pautado nas leis, que, na verdade, são complementares ao argumento teórico que admite uma distribuição homogênea de virtude entre os homens.

A partir da importância concedida a Aristóteles entre as diferentes combinações das formas mistas de governo, Sidney pôde aceitar como um dado histórico que a virtude encontra-se distribuída de modo mais ou menos homogêneo entre os homens, uma vez que os extremos, em geral, são menos observados (Lurbe, 2004, p. 39) e, especificamente, raríssimas vezes a virtude encontra-se concentrada em um ou em poucos de modo a justificar um governo natural (Scott, 1991, p. 225). De fato, nos termos da linguagem empregada por Sidney, que, em parte, foge dos modos esquemáticos da classificação aristotélica, a variabilidade das formas de governo é de tal monta que cada uma é sui generis e, a partir de tamanha pluralidade, a redução em três regimes somente pode ser aceita em termos analíticos e abstratos (cf. Falcão, 2019, p. 228). Compreendese daí que os critérios de um, poucos e muitos sejam indicações ideais que apenas muito raramente encontram realização. Assim, não há razão para, dadas as barreiras para se reconhecer e estabelecer o governo virtuoso, creditar à virtude os regimes historicamente verificáveis ${ }^{\mathrm{x}}$.

Isso leva a um ponto interessante do sistema de Sidney. Em tese, o melhor governo é aquele sustentado na virtude, como mostram os casos hipotéticos da monarquia natural, da aristocracia natural e do povo conquistado por um virtuoso, mas as dificuldades práticas forçam a necessidade do império da lei (Sidney, 1996a, p. 82). Os exemplos provam que os fracassos da união entre virtude e rei ou virtude e aristocracia superam, em muito, os sucessos, logo, aquilo que teoricamente se apresenta como a melhor solução não encontra lugar na história (Sidney, 1996b, p. 350; cf. Worden, 1985, p. 16-22). A plausibilidade da hipótese é mantida, a de que 0 melhor dos governos é aquele do mais virtuoso, tão somente pelo fato de que Sidney não pode deixar de reconhecer que, em algum nível, deve manter-se a aberta a possibilidade de os homens serem diferentes uns dos outros, mas que, ainda que isso ocorra, não deve tal situação produzir arbitrariedade, erro, vício e injustiça.

É necessária uma última palavra sobre a relação entre a virtude e a razão humanas. Fica claro que no sistema teórico de Sidney, virtude e razão não são igualmente encontradas em todos os homens, a primeira, se e quando ocorre em alguém é raríssima, enquanto a segunda, por ser uma lei da natureza, reside em todos, bastando para acessá-la consultar o próprio coração. Dentre as principais faculdades da razão está a de reconhecer os mais virtuosos, inclusive a própria virtude em relação aos demais. Desse modo, o exemplo de Alexandre, cujo governo era 
simultaneamente virtuoso e autárquico, além de exceção, refere-se ao fato de que ele próprio sabia que era o mais virtuoso dos homens e os demais também o reconheciam como tal. A virtude, assim, é uma reminiscência divina, em suas palavras, uma "luz da natureza" (light of nature), embutida nos homens por Deus, que confere àqueles que agem dentro de seus conformes não apenas a lei natural como razão, mas, antes de tudo, a luz divina (Sidney, 1996a, p. 95; cf. Houston, 1991, p. 215). O problema se dá justamente no fato de que, pela condição da lei da natureza como liberdade, os homens são livres o suficiente para descumprirem os ditames da razão (Barros, 2018, p. 75), mesmo os mais virtuosos, por desregramento da vida ou por mero capricho individual. Pela imposição da liberdade física, a razão humana não é suficiente para que se estabeleça o melhor dos governos, ainda que todos reconheçam os homens mais virtuosos há sempre quem lhes negue o governo, em um evidente atentado contra a própria razão. A única forma de contornar esse capricho humano é pela coerção das leis.

\section{3. $O$ governo das leis}

Segundo Sidney, dentre as leis existentes no universo, iniciada pela lei de Deus e da natureza, as leis positivas representam a maior variabilidade, por dependerem tão somente da vontade dos homens, em cada circunstância que os faz confeccionar leis e instituições. O que determina as leis criadas pelos homens não é senão a tensão entre as diferentes vontades envolvidas em um determinado contexto político (Sidney, 1996a, p. 123; Sidney e Jones, 1689, p. 176). Isso significa que, a fim de que se identifique uma lei positiva que contrarie a lei natural racional, basta um único contraexemplo, este, pois, é uma exceção que confirma sua origem mundana. "Se elas [as leis positivas] não são as mesmas em todos os lugares, reis não reinam por uma lei universal, mas por leis particulares de cada país que podem dar a cada um o poder suficiente para [...] pôr fim ao cumprimento do bem público" (Sidney, 1996b, p. 113). É fato contingencial no mundo humano que os reis - e aristocratas - sejam os governantes e, mais contingencial ainda, que um determinado rei - ou aristocrata - seja um bom governante, por isso, essas instituições são, geralmente, tendencialmente autodestrutivas. A partir de tal contingência, que remete a qualquer expressão da lei positiva, Sidney deriva seu argumento para o governo das leis.

Se é isso [a veracidade do direito hereditário dos reis], então, é ridículo e absurdo. É certo que o nome e o ofício de rei, cônsul, ditador ou similares, não confere qualquer direito determinado à pessoa que o tem. Todos têm o direito ao que é alocado nele a partir das leis do país pelas quais ele é criado. (Sidney, 1996b, p. 114)

Fica claro que o título governante de alguém depende, antes de tudo, das leis e, por isso, todos podem, sob determinadas circunstâncias, desfrutar dele no exercício de um mandato. Uma vez que as leis positivas não passam de invenção humana, a igualdade desfrutada sob o governo delas é analogamente uma invenção humana estabelecida no ato do contrato que cria a soberania (Sidney, 1996a, p. 101; cf. Scott, 1988, p. 58). O aspecto contratualista de Sidney requer o entendimento preciso da função das leis em uma sociedade. Qualquer homem tem a liberdade e capacidade de optar por viver ou não em sociedade, esse ato voluntário e unilateral pode ser entendido individual ou coletivamente (Sidney, 1996b, p. 35; cf. Hamel, 2011, p. 99). Todavia, uma sociedade civil somente pode ser constituída quando os envolvidos na sua construção entendem que os benefícios superam os inconvenientes, como a segurança, o progresso das artes e ciências e o bem público e privado (Sidney, 1996b, p. 22; Sullivan, 2006, p. 74). É necessário, porém, sempre ter em conta que esses inconvenientes jamais desaparecem. Em geral, eles advêm das relações recíprocas e dos atritos provocados pela interação entre os homens. A artificialidade das instituições políticas visa mitigar as divergências privadas oriundas apenas do contato dos humanos uns com os outros. Repare-se que do inconveniente advindo do distanciamento do "estado natural dos homens" deve-se repará-lo por uma artificialidade ainda mais forte, que a todos subordine e iguale, qual seja, as leis artificiais. 
De um lado, a sociedade civil protege os homens dos males do estado de natureza, de outro, produz inconvenientes que devem ser, de algum modo, sanados ou dirimidos e isso deve ser feito por regras gerais às quais todos irrestritamente devem se submeter (Sidney, 1996b, p. 192). "A sociedade na qual vivo não pode subsistir senão pela regra. A igualdade na qual todo homem nasce é tão perfeita que nenhum homem tem sua liberdade natural reduzida, exceto se todos fizerem o mesmo" (Sidney, 1996b, p. 548). O mais evidente dos inconvenientes da formação das sociedades é a necessária criação de regras que estipulem as sanções àqueles que, utilizando da liberdade natural determinada pela lei da natureza, adentrem ao direito alheio. Uma vez formada a sociedade civil, ela progride e se torna cada vez mais complexa (Sidney, 1996b, p. 512). Com isso, emerge a necessidade de leis: "Por esses meios, todos os homens, concordando juntos (agreeing together) e formando uma sociedade, se tornam um corpo completo, tendo todo o poder em si mesmos sobre si mesmos, submetidos a nenhuma outra lei humana que não as suas próprias" (Sidney, 1996b, p. 99). Portanto, é a partir dos inconvenientes após a formação da sociedade que o governo surge por um segundo contrato no qual seu alicerce é a lei (Sidney, 1996b, p. 327; cf. Robbins, 1947, p. 283). Repare-se que não há mecanismo legítimo de formação de um regime legal que não seja a autoimposição unânime de todos para com todos e em relação a todos, isso é, um autogoverno cujas leis restrinjam a liberdade natural de todos igualmente. Por isso, ao restringir igual e voluntariamente as liberdades naturais de todos os contratantes, mantêm-se todos eles iguais, uns em relação aos outros.

Devido ao fato de ser um artifício humano, o contrato que institui o governo não é capaz de aniquilar as leis da natureza, mesmo a mais fraca lei da natureza como razão, mas pode, sim, agir contrariamente a ela (Sidney, 1996b, p. 104) e, quando isso ocorre, então, o homem que consulta o coração tem o dever moral de agir - o exemplo clássico é o tiranicídio -, embora não exista nada que o obrigue a fazê-lo (Worden, 1985, p. 15). Assim, a lei da natureza como razão serve de guia para as leis humanas de tal maneira que o esforço legislativo deve simultaneamente absorver o caráter legalista e racional. Por pressuposto, se a lei positiva desautorizar a lei da natureza como razão, o governo se torna ilegítimo, por definição.

Entende-se aqui o motivo que levou Sidney, como vimos acima, a afirmar que mesmo os governos legais são arbitrários, o que importa, na verdade, é a qualidade do governo, seja a partir de um virtuoso ou de leis que produzam o bem público (Sidney, 1996a, p. 9-10). O argumento favorável ao governo das leis, para além do impeditivo prático de não haver um virtuoso, se ancora em um artifício humano capaz de igualar politicamente todos os cidadãos ${ }^{\mathrm{xi}}$. Desse modo, o governo das leis funciona como um quesito necessário à sustentação da isonomia em uma república. Nesse ponto, ele se difere substancialmente do governo do(s) virtuoso(s). A natureza distribuiu a virtude de modo relativamente aleatório entre os homens, de forma que na contingencial situação na qual ela se encontra concentrada, o governo a partir dela é o melhor. Assim, da virtude introjetada em poucos homens se constata a desigualdade natural deles todos; quando homogeneamente distribuída, observa-se o imperativo legalista produtor de igualdade em termos exclusivamente políticos. Dependendo das circunstâncias, a igualdade ou a desigualdade deve ter primazia uma sobre a outra, respectivamente, quando a virtude for distribuída homogeneamente ou não.

Todavia, observando a aleatoriedade e relativa homogeneidade da distribuição das virtudes pelo mundo, confere-se que as monarquias e aristocracias são extremamente parcas, sobrando, pois, a democracia ou governo popular. É verdade que Sidney não é um defensor do regime democrático em si mesmo, por vezes, seu argumento pende ao aristocratismo (Sidney, 1996a, p. 58), mas é igualmente evidente que o governo das leis, por necessidade, se coaduna com o governo misto e o autogoverno (Sidney, 1996a, p. 12-13). Uma nação que calibra seus poderes equilibradamente e governa para si mesma como um corpo político unido e coeso não pode se dar ao luxo de tratar cidadãos iguais de maneira diferente (Sidney, 1996a, p. 34-35). Nessas condições, a participação popular, direta ou através de representantes, se apresenta legítima 
(Sidney, 1996a, p. 162; Sidney e Jones, 1689, p. 167-171; Sidney e Penn, 2002, p. 386).

Mas, independentemente disso, as leis possuem uma vantagem sobre o governo do virtuoso: sua durabilidade. "Leis devem mirar a perpetuidade, mas as virtudes de um homem morrem com ele e muito comumente antes dele" (Sidney, 1996b, p. 559; cf. Sidney, 1996a, p. 27). Essa durabilidade incide diretamente no desenvolvimento do progresso humano, no respeito às instituições públicas, na legitimidade do direito criminal, na previsibilidade do governo (Sidney, 1996a, p. 122); em suma, na promoção da boa ordenação da república. $E$, entre os termos que promovem a república bem-ordenada reside a própria virtude.

De modo similar ao reconhecimento de que, em regimes governados por virtuosos, as leis não passam de seus instrumentos, quando o governo das leis se faz eminente, elas devem favorecer a virtude. "Leis são feitas e governos constituídos como remédios para a fragilidade e depravação humanas. Apenas são boas as leis que permitem e encorajam a virtude e punem o vício" (Sidney, 1996a, p. 196). Confirma-se assim uma via de mão dupla entre as opções de governos dos homens ou das leis que conformam, em algum nível, um grau relevante de interdependência. No primeiro caso, as leis são instrumentos, no segundo, a virtude deve ser encorajada. A suposição inicial, constantemente aceita no pensamento republicano moderno, de que governo das leis e governo dos homens (mesmo homens de virtude) são contraditórios é radicalmente dirimida, embora jamais findada. Seria um esforço inócuo as leis promoverem a virtude quando se sabe que ela não emergirá do público, mas não devem fechar as portas caso isso ocorra. Portanto, o pressuposto é de que o homem de virtude deve ser encorajado e não limitado pela lei. Dito de outro modo, as leis devem sempre estar atentas ao surgimento de um homem virtuoso e, com isso, abdicar de sua função isonômica original de modo a compatibilizar a desigualdade natural dos homens com a boa ordenação se, e somente se, de fato, esse homem existir. Se o governo das leis positivas existe porque a lei da natureza como razão pode ser descumprida, então, cabe-Ihes a responsabilidade por favorecer nos homens a virtude perdida sem que, com isso, a lei da natureza como liberdade seja desrespeitada. Mas para se manter a liberdade em um regime no qual as leis igualam todos, é preciso que ela se transforme de natural para civil. A liberdade civil é incapaz de limitar o movimento físico, por isso, a liberdade natural se mantém em estado civil, o que permite o descumprimento da lei positiva, incluindo quando isso for um dever, como no caso do tiranicídio. Por outro lado, a liberdade civil é estritamente relativa, quando todos concordam em não agir contrariamente às leis positivas a fim de criar o autogoverno equânime.

\section{Conclusão}

O pensamento republicano moderno, em grande medida, aborda a tensão entre governo dos homens e governo das leis favorecendo o segundo. Porém, quando se qualifica o primeiro a partir do entendimento de que se trata de homens de virtude, o cenário se torna mais complexo. A solução para essa questão é quase sempre formulada a partir da constatação de uma determinada situação conjuntural. Quando em crise - sob a ameaça de uma tirania ou de uma invasão estrangeira, por exemplo -, a nação necessita de um homem virtuoso o suficiente para restabelecer a boa-ordenação e a liberdade então em xeque. Quando em conformidade com o andamento ordinário dos negócios públicos, a lei impera e garante a rotina da cidade. Autores distantes ou refratários ao jusnaturalismo - como Maquiavel e Harrington - tendem a conceder destaque à figura do fundador ou do reformador de repúblicas que, uma vez cumprida a tarefa, se afasta da cidade fundada e lega ao futuro sua obra constitucional. Todavia, a salvação da cidade ameaçada se origina no aparecimento de um virtuoso. É apenas a avaliação do caso concreto que permite a emissão de juízo sobre a legitimidade do descumprimento das leis, nenhuma teoria pode ser estabelecida a priori.

$\mathrm{O}$ argumento da superioridade natural do mais virtuoso foi utilizado, desde a reentrada da Política aristotélica no Ocidente, para justificar principados e monarquias. Porém, é sugestivo que seja também no terceiro livro da Política no qual Aristóteles estabelece a naturalidade do governo 
do mais virtuoso. Ele destaca que a monarquia natural é semelhante ao governo doméstico, na comparação do povo com os membros submetidos ao líder de uma casa. Em ambos os casos, no governo da cidade (pólis) e da casa (oikós) trata-se da unidade entre o bom homem e o bom cidadão e aquele que prepondera em extrema virtude não compõe a cidade como outro qualquer e é, de fato, "um deus entre seres humanos" (Aristóteles, Política, 1284a). O fato dessas passagens terem inspirado os mais diversos monarquistas, dentre eles Robert Filmer, é particularmente significativo pelo exacerbado antimonarquismo de Sidney, mas que não o impede de concordar com o filósofo de Estágiros nesse quesito. Malgrado Filmer ter uma obra inteira dedicada à análise das formas de governo em Aristóteles (Observations upon Aristotle's Politiques touching forms of government), muito provavelmente Sidney não teve acesso a esse texto, apenas ao Patriarcha. Nesse, afirma Filmer (1949, p. 76) que, para Aristóteles, não há diferença entre uma casa grande e uma cidade e que o filósofo concorda com as escrituras de que não há liberdade natural (Filmer, 1949, p. 79). Cabe, portanto, questionar as razões que levaram Sidney a empregar um artifício tão caracteristicamente monárquico e tão próximo de seu principal adversário, Filmer. Na verdade, se observado o sistema de Sidney com cautela, perceber-se-á que, com o exemplo antigo de Alexandre e o ficcional de Hércules (Sidney, 1996b, p. 389-390), o rei natural não existe, pois não ocorrem verificações históricas. A hipótese de um governante natural é mantida por ele como um modo retórico de convencimento, via atração de seus adversários, dos monarquistas através de uma suposta concordância inicial sua com a monarquia natural. Levado ao limite, é preciso aceitar que Sidney não discorda sequer de Filmer sobre a naturalidade do monarca por características inatas. A única diferença entre os dois residiria no fato de que Filmer julga ser o monarca natural pelo critério de hereditariedade e patriarcalismo e Sidney de virtude, ambos, caracteres inatos. Uma importante evidência disso é que Filmer censura Aristóteles por esse julgar que o homem "mais sábio" (Filmer, 1949, p. 80) é o governante natural e não o primogênito oriundo da linhagem de Adãoxii. A condição fundamental que Sidney restringe a naturalidade do governo do mais virtuoso é sua realização histórica, o que lhe basta para rejeitar toda e qualquer forma de monarquia e mesmo de aristocracia.

A particularidade de Sidney, consonante à sua aderência jusnaturalista, reside na justeza da manutenção simultânea da virtude e da legalidade, o que nos permite identificar, a priori, as situações nas quais as leis ou os homens imperam. "Em uma república, portanto, leis bemconstituídas governam, não homens" (Sidney, 1996a, p. 196). Mas o governo é igualmente republicano e bem-ordenado "quando um homem de valor, justiça e sabedoria admiráveis se ergue em um povo livre, excedendo cada um e todos juntos; então, eles voluntariamente se submetem ao seu governo, uma vez que excede em todas aquelas virtudes que conduzem ao fito para o qual o governo é constituído" (Sidney, 1996a, p. 203). Por natureza, os homens são livres para seguir ou não a razão natural e, desse modo, se os virtuosos não desrespeitarem a lei da natureza como razão, a república será bem-ordenada. Por isso, pode ele afirmar que "todas as monarquias do mundo que não são puras barbáries e tiranias sempre foram chamadas de repúblicas" (Sidney e Jones, 1689, p. 184). O recurso legalista, portanto, é secundário em relação à virtude, mas frequentemente necessário a fim de coibir a tirania ou o mal governo (Sidney e Jones, 1689, p. 174). Do ponto de vista institucional, é pouco relevante a quantidade de homens que compõem o governo, importando, pois, a qualidade de todos e cada um na medida em que virtude e lei se completam mutuamente. Nesse sentido, convém ao republicanismo de Sidney coadunar o governo dos homens virtuosos com o das leis não em situações de crise ou calmaria, respectivamente, mas quando a virtude se apresentar ao público ou quando a lei da natureza como razão for desrespeitada. Assim, lei e virtude formam um par intercambiável e interdependente. Seja através do governo das leis, seja do governo do homem virtuoso, o fato é que ambos os paradigmas são atributos constantes do republicanismo moderno e a marcante contribuição de Sidney incide justamente no fato de oferecer um esquema teórico e universal para a aplicação de cada um desses termos. 
(Recebido para publicação em agosto de 2019)

(Reapresentado em outubro de 2019)

(Aprovado para publicação em dezembro de 2019)

\section{Cite este artigo}

FALCÃO, LUÍS, 2019. Algernon Sidney: a tensão entre virtude e legalidade. Revista Estudos Políticos: a publicação semestral do Laboratório de Estudos Hum(e)anos (UFF).Rio de Janeiro, Vol.10 |N.2, pp.220-235, dezembro de 2019.

\section{Notas}

1. Algernon Sidney (1623-1683) foi um militar inglês de família nobre que se envolveu diretamente em campanhas na Irlanda e no continente, além de ter atuado como embaixador na Dinamarca um pouco antes da Restauração Stuart. Membro do Longo Parlamento e crítico do Protetorado, sempre defendeu a tolerância religiosa e a liberdade, para as quais o regime republicano seria o mais adequado, apesar de sua oposição ao regicídio de 1649 . Por conta de suas posições, viveu grande parte de sua vida no exílio, viajando por diversos países europeus e retornando à Inglaterra em 1677. Sidney foi executado em 1683, acusado, a partir dos manuscritos de sua principal obra, Discourses Concerning Government, de conspiração contra o rei. O texto, nunca terminado, foi publicado apenas em 1698, e conta com importantes edições no século XVIII. Registram-se ainda as Court Maxims, escrito possivelmente em 1665, mas descoberto apenas no século XX; A Just and Modest Vindication of Proceedings of the two last Parliament, único texto publicado em vida com sua assinatura, em parceria com William Jones; An Essay on Love, um pequeno tratado sobre a natureza humana e suas paixões; um texto em coautoria com William Penn, England's Great Interest, in the Choice of This New Parliament; além de um curtíssimo escrito de cunho religioso, A Prophesy of St. Thomas the Martyr e uma apologia a Henry Vane, seu amigo e político inglês. A maior parte de suas cartas, familiares e políticas, foram publicadas em diferentes edições, particularmente no século XIX. O recente interesse acadêmico por Sidney se soma em grande medida à retomada dos estudos sobre o republicanismo. Sua biografia mais completa é Algernon Sidney and the English Republic e Algernon Sidney and the Restoration Crisis de Jonathan Scott. Tivemos que limitar as fontes secundárias neste artigo de modo a contemplar as principais contribuições ou as que tratam diretamente do assunto em tela, de tal maneira que temas importantes e de destacado interesse de seu pensamento não puderam ser discutidos. Para uma bibliografia 
mais completa sobre Sidney, alguns aspectos teóricos gerais do republicanismo e, particularmente, sobre o republicanismo inglês, cf. Barros (2018, p. 194-206) e Falcão (2019, p. 275-290).

2. Deve-se ter claro que essa liberdade não se aplica à situação de sociedade civil ou ao Estado, apenas no "estado natural dos homens", o que configura uma diferença substancial com Hobbes (Barros, 2018, p. 75; Falcão, 2019, p. 88). Apesar de sua principal obra, os Discourses Concerning Government, ter por alvo central o Patriarcha de Robert Filmer, em moldes similares ao primeiro dos Two treatises of government de John Locke e Patriarcha non Monarcha de James Tyrrell (Daly, 1979, p. 160-162), o desenvolvimento conceitual da lei da natureza como liberdade se desdobra tendo por base a tradição jusnaturalista, particularmente, na figura de Hobbes. Não cabe neste estudo um cotejo teórico entre os autores, a referência a Hobbes visa tão somente contribuir para a clareza do argumento.

3. Essa distinção com Hobbes se assenta, em grande medida, à mobilização de pensadores jesuítas como Francisco Suaréz e Roberto Bellarmino. Porém, é preciso destacar que essa contrariedade entre identificar os ditames morais divinos e liberdade natural é uma contribuição substancial do próprio Sidney.

4. É preciso ter em vista que a diferença entre o conceito de liberdade em Hobbes varia de obra para obra. Nos Elementos do direito natural e político (Hobbes, 2011, cap. XVIII) e no De Cive (Hobbes, 1983, cap. IV), o autor afirma que uma característica limitante do movimento, mas que seja interna ao próprio ser, como a paixão ou a doença, limita a liberdade. Porém, no Leviatã, Hobbes difere liberdade de poder ou capacidade, de tal maneira que estar incapacitado/ limitado pela paixão ou doença não é estar restrito de liberdade, mas de poder. Para a justificativa dessa mudança inserida no debate e desenvolvimento das ideias republicanas, cf. Skinner (2008). Essa distinção é relevante para Sidney porque, em nenhum momento, ele difere liberdade interna ou externa, o que significa que segue, como atestam as suas citações, o Leviatã.

5. Não é possível desenvolver aqui o conceito de virtude em Sidney, mas, em linhas gerais, ele segue os preceitos tradicionais ciceronianos, revigorados pelo cristianismo e, em alguma medida, também pelo humanismo italiano. Trata-se, em suma, das quatro virtudes cardeais nas quais uma completa as demais. Sobre isso, cf. Falcão (2019, p. 182-190).

6. Esse ponto constitui uma distinção importante com o liberalismo clássico, expressamente na figura de Locke, porquanto se saiba que a alienação da própria liberdade é im- 
possível e uma contradição em termos, ainda que constitua o bem e o melhor para aquele que se aliena. Cf. Barros (2018, p. 87).

7. Alguns autores mobilizados por Sidney - Cícero (As Leis, III, I, 2) e George Buchanan (De Iure Regni apud Scotos Dialogus) - empregam a noção de "lei viva" ou "lei falante" para se referirem ao magistrado justo e obediente às leis civis e, do mesmo modo, empregam "magistrado mudo" a fim de designar as leis escritas. Sidney retira das duas imagens a compatibilidade entre o governante virtuoso e as leis. É preciso destacar, porém, que Sidney conduz sua análise mais intensamente voltada para a virtude.

8. Aliás, levado o argumento ao limite, deve-se reconhecer que é uma contradição em termos existir um rei legítimo cuja virtude não supere a soma das virtudes de seus súditos, pois na situação na qual a virtude seja relativamente homogênea entre os homens, o único governo legítimo é o popular ou de todos. Portanto, um rei que não se distinga em virtude, não é senão um tirano e, por isso, a função limitadora da lei se transforma na deposição do governante.

9. Dos exemplos prediletos de Sidney, a bebedeira é o mais empregado (Sidney, 1996b, p. 82 e 158; cf. Scott, 1988, p. 146), porque ofusca o entendimento e a razão. Isso mostra a necessidade de regramento na vida para a manutenção da virtude. Ela é interna, nata e original, mas para mantê-la é preciso que haja uma predisposição moral e uma contínua ação para isso. Cf. Robbins (1947, p. 275).

10. De acordo com Sidney, e como é bastante comum entre pensadores jusnaturalistas, as formas de governo possuem uma importância secundária frente a seus princípios gerais e justificativas. Porém, mesmo não sendo o principal recurso, Sidney não deixa de comentar a variabilidade e classificação das formas de governo. Cf. Falcão (2019, p. 201).

11. Esse argumento é provavelmente também inspirado em Aristóteles (Política, 1287b).

12. Observe que Filmer opta por traduzir areté por sabedoria e não, como já era comum e como empregará Sidney, como virtude. Isso é sintomático porque Filmer comenta detalhadamente um conjunto de traduções inglesas e francesas, acusando-as de inserir no texto aristotélico versões da igualdade natural supostamente inexistentes no original grego.

\section{Referências bibliográficas}

ARISTOTLE. (1958), The Politics of Aristotle. Edited and translated by Ernest Barker. Oxford: Oxford University Press. 
Ross and revised with an introduction and notes by Leslie Brown. Oxford: Oxford University Press.

BARROS, Alberto R. G. (2018), Republicanismo inglês: Sidney e a semântica da liberdade. São Paulo: Discurso Editorial.

CARRIVE, Paulette. (2007), "La tyrannie, le diable, la monarquie, la république dans le Court Maxims d'Algernon Sidney", in ZARKA, Yves-Charles (ed.). Monarchie et république au XVII siècle. Paris: PUF.

DALY, James. (1979), Sir Robert Filmer and English political thought. Toronto: University of Toronto Press.

FALCÃO, Luís. (2019), Algernon Sidney: um pensador republicano do século XVII. Niterói: EdUFF.

GEUNA, Marco. (2013), "The tension between Law and Politics in the Modern Republican Tradition", in SCHINK, P. e NIEDERBERGER, A. (orgs.). Republican democracy. Liberty, law and politics. Edinburgh: Edinburgh University Press.

HAMEL, Christopher. (2011), L'Esprit Républicain: droits naturels et vertu civique chez Algernon Sidney. Paris: Garnier.

HOBBES, Thomas. (1983), De Cive (1642). Oxford: Clarendon Press.

. (1985), Leviathan (1651). London: Penguin.

. (2011), The elements of law, natural and political (1640). Oxford: Clarendon Press.

HOUSTON, Alan Graic. (1991), Algernon Sidney and the Republican Heritage in England and America. Princeton: Princeton University Press.

LURBE, Pierre. (2004), "Le républicanisme belliciste d'Algernon Sidney". Cercles, $11:$ 32-44

PEÑA, Javier. (2004), "Ciudadanía Republicana y Virtud Cívica", in BERTOMEU, María Júlia, DOMĖNECH, Antoni y FRANCISCO, Andrés de (orgs.). Republicanismo y Democracia. Madrid y Buenos Aires: Minõ y Dávila Editora.

FILMER, Robert. (1949), Patriarcha and other political works. Edited by Peter Laslett. Oxford: Oxford University Press.

PINZANI, Alessandro. (2005), "Repubblicanesimo e democrazia liberale: un binomio inconciliabile?" Annali del Dipartimento di Filosofia, 2003-2004. Firenze: Firenze University Press.

ROBBINS, Caroline. (1947), "Algernon Sidney's Discourses Concerning Government: the Textbook of Revolution". The William and Mary Quarterly. 4, 3: 267-296

SCOTT, Jonathan. (1988), Algernon Sidney and the English republic: 1623-1677. Cambridge: Cambridge University Press. 
crisis: 1677-1683. Cambridge: Cambridge University Press.

SIDNEY, Algernon and PENN, William. (2002), England's Great Interest, in the Choice of This New Parliament (1679), in PENN, William. The Political Writings of William Penn. Indianapolis: Liberty Fund.

SIDNEY, Algernon and JONES, William. (1689), A Just and Modest Vindication of Proceedings of the two last Parliament (1681), in State Tracts of the Reign of Charles II. London. (vol. 4)

SIDNEY, Algernon. (1795), An Essay on Love (1640-1660?), in The Essence of Algernon Sidney's Work on Government, to which is annexed his Essay on Love. London: Printed for John Jonson, St. Paul's Church-Yard.

Cambridge: Cambridge University Press.

$$
\text { (1996a), Court Maxims }
$$

(1665?).

. (1996b), Discourses concerning government (1683). Indianapolis: Liberty Fund.

SKINNER, Quentin. (2008), Hobbes and republican liberty. Cambridge: Cambridge University Press.

SULLIVAN, Vickie. (2006), "The reconciliation of Machiavellian Republicanism with liberalism in Sidney's Discourses Concerning Government and Trenchard's and Gordon's Cato's Letters", in RAHE, Paul (org.). Machiavelli's liberal republican legacy. Cambridge: Cambridge University Press.

WINSHIP, Michael P. (2010), "Algernon Sidney's Calvinist republicanism". Journal of British Studies. 49, 4: 753-773

WORDEN, Blair. (1985), "The commonwealth kidney of Algernon Sidney". Journal of British Studies. 24, 24: 1-40. 